\title{
Creating Creative Thinking in Students: A Business Research Perspective
}

\author{
Nitaya Wongpinunwatana ${ }^{1}$, Kunlaya Jantadej ${ }^{1} \&$ Jamnong Jantachoto $^{2}$ \\ ${ }^{1}$ Thammasat Business School, Thammasat University, Bangkok, Thailand \\ ${ }^{2}$ Faculty of Business Administration, Rajamangala University of Technology Phra Nakhon, Bangkok, Thailand \\ Correspondence: Nitaya Wongpinunwatana, Thammasat Business School, Thammasat University, Bangkok, \\ Thailand.
}

Received: January 23, 2018

Accepted: February 12, 2018

Online Published: February 23, 2018

doi:10.5539/ibr.v11n4p47

URL: https://doi.org/10.5539/ibr.v11n4p47

\begin{abstract}
The objective of this study is to investigate how to create creative thinking in students through encouraging students' logical thinking, motivation, and collaborative learning. The study also attempts to find suitable teaching procedures for the research subject. This study is based on qualitative research. Participants were graduate students studying business research methods. The results indicate that logical thinking affects the analytical skill. This skill, in turn, affects students' creative thinking. A model of creating creative thinking in students is proposed from the research findings. Instructors may consider using the modeling to boost creative thinking in students. In addition, the findings suggest that the main teaching processes should be as follows: Instructors should encourage students to use their logical reasoning during the conceptual framework development. Workshops on students' research projects should be conducted so students can practice doing research. Students should make oral presentations of their projects and experts invited to comment on them. Collaborative technologies need to be introduced so that instructors and students can communicate with each other on assignments. Apart from collaborative tools, instructors can set up additional sessions after hours to allow students to discuss problems they are facing. Research classes should incorporate in the coursework three student presentations: problem statement, research proposal, and completed research report. Finally, instructors should form students into groups and establish roles for the members.
\end{abstract}

Keywords: creative thinking, motivation, collaborative learning, logical thinking

\section{Introduction}

Teaching students to possess logical and creative thinking conforms to academic reformations adopted in Thailand, which intend to teach students to think critically. In addition, this teaching complies with the 11th National Economic and Social Development Act. This act aims to improve the educational achievement of Thai people, not only regarding quantitative aspects, but also by initiating a new body of knowledge to increase competency needed to compete with other countries. However, this new body of knowledge needs academic discipline and scholarly instruction in the subject of research (Office of the National Economic and Social Development Board, 2015). Moreover, effectively and efficiently analysing and synthesizing existing knowledge requires logical and critical thinking skills. These skills are incorporated in successful research processes. This statement agrees with Zhao (2009), who states that teachers could train MBA students to analyse effectively and efficiently by using logical thinking.

To help solve these problems, instructors can incorporate logical thinking into the research subject (Laney, 2001). Although logical thinking results from cumulative personal experiences gradually collected over a long time, teachers can choose instructional methods that accelerate the learning process to develop this principle more rapidly (Rimanoczy, 2007; Zhao, 2009). Therefore, the purpose of this research is to examine the nature of logical thinking and how it can develop and enhance students' creative thinking. In addition, this research attempts to find suitable teaching procedures for the research subject.

\section{Theoretical Background}

\subsection{Creative Thinking}

Students possessing creative thinking ability demonstrate this in the form of inferences, interpretations, and 
assumptions; as well as the determination of concepts, theories, principles, definitions, and frames of reference (Paul and Elder, 2011). The ability to form inferences originates from logical thinking. Logical thinking comes from learning from other people's mistakes and actions. These experiences and actions, if reasonably thought through, help students to cope with difficult situations successfully (Rimanoczy, 2007; Zhao, 2009). Normally, people use logical thinking to make decisions by simplifying complex situations to simple solutions (Morgan and Thiangarajan, 2009).

Creative thinking and critical thinking are often inseparable. Critical thinking is the ability to think clearly and rationally about what to do or what to believe. Critical thinking is an essential part of creative thinking, because people need critical thinking to evaluate and improve their creative ideas (Lau and Chan, 2004; Nimalathasan and Valeriu, 2010). New ideas generated from creative thinking must be useful and relevant to the problems if they are to be fixed. Critical thinking plays a crucial role in evaluating new ideas, in selecting the best ones and in modifying those ideas as necessary (Lau and Chan, 2004; Paul and Elder, 2011).

\subsection{Motivation in Education}

One of the important components in the study of research is motivation. Students' motivation plays a crucial role in learning the conceptual process, critical thinking process, and information processing skill (Cavas, 2011). The instructor's level of motivation is an important factor that relates to students' creative thinking (Horng et al., 2005; Davis et al., 2014; Palaniappan, 2014). Motivation is an important educational variable that can promote new learning, strategies and behaviours, and skills. If students perceive the value of learning tasks, they will actively participate in those tasks to construct a meaningful understanding of a new concept based on their existing knowledge (Cavas, 2011).

Cavas (2011) concludes that there are six categories of motives: self-efficacy, active learning value, active learning strategies, performance goal, achievement goal, and learning environment stimulation. Self-efficacy is students' beliefs about their own ability to perform well in learning tasks. The active learning value consists of acquiring problem-solving competency, stimulating their own thinking, and finding the relevance of learning. Active learning strategies are a variety of strategies to construct new knowledge based on previous understanding. The performance goal is students' competition with other students in the classroom to get recognition from the teacher. The achievement goal is students' satisfaction as they increase their competence and achievement during learning. Finally, the learning environment stimulation is comprised of learning environment factors such as curriculum, teaching style, and learner collaboration.

\subsection{Collaborative Learning}

Collaborative learning is a joint effort by all participants within a group of students, where they work together to search for understanding, meaning, or solutions to accomplish a task (Hong, 2011). Collaborative learning requires individuals to take responsibility for a specific section and then coordinate their respective parts together (Kyndt et al., 2013). Knowledge can be created within members in a group where members actively interact by sharing experiences and take on asymmetric roles (Mitnik et al., 2009). Collaboration can be structured in the form of group-based collaboration or idea-centred collaboration (Hong, 2011). Group-based collaboration is the method where each student within a group is assigned to complete a subtask and then the subtasks are merged together like a jigsaw puzzle. Idea-centred collaboration is the method where students work together without forming a group or having a general plan.

Collaborative learning is very important in achieving critical thinking ability (Gokhale, 1995). Individuals are able to learn effectively and efficiently and retain more information when they work together in a group rather than individually (Gokhale, 1995; Hong, 2011). Technology has become an important factor in collaborative learning. The internet allows individuals to share personal knowledge and ideas. In addition, collaborative learning which uses technology in a learning environment supports group interactions, which in turn mediates the acquisition of new knowledge (Mitnik et al., 2009).

\subsection{Compatibility with Teaching Methods}

Various theories from cognitive psychology (see e.g., memory theory, cognitive learning theory, mental model theory and cognitive-fit theory) have been adopted by researchers to explain the effect of teaching methods on user's performance in problem solving. Howe ver, some previous empirical studies of teaching and learning show mixed results on the benefits of the teaching methods in improving users' performance in learning (Murphy, 1990; Eining and Dorr, 1991; Gregor, 1996). A plausible reason may be the appropriateness of theory used to predict the results. Activity theory may be able to explain the contrast previous research results.

Activity theory is wildly used in education and training. This theory can be used to explain the learning process 
(Engeström et al., 1999). This theory comprises of five related elements: subject, object, community, tools and division of labour. First, subject is actors engaged in the activities. The activity theory considers subject as a team instead of one actor. Second, object can be thing which is tangible and/or intangible. The object, however, should represent the reality. Third, community is a group of actors involved in the activity system. In instructor-led teaching and demonstration, lecturer, normally, is the only one who conducts the activities. Fourth, tools can be anything used by actors in accumulation and transformation of knowledge. Finally, division of labour is hierarchical structure of activities among actors in accumulation and transmission of knowledge.

Numerous teaching methods are available for instructors to use in the classroom (e.g., Laney, 2001; Taylor, 2013). As this research puts an emphasis on teaching techniques that enhance students' creative thinking, the most commonly used teaching methods will be reviewed. These teaching methods include: concept-based instruction, role-playing, and case-study approach. The choice of teaching methods depends largely on the subjects that are being taught; the choice may also be influenced by the enthusiasm of the students (Taylor, 2013). Concept-based instruction is the process involved with teaching the general concept definition. This method tends to be more appropriate when teachers want to instruct students with precise definitions and concepts. Role-playing is an experience-based instruction. Role-playing activities are often employed within the format of a simulation. Simulations replicate the essential characteristics of the real world. A case study is normally based on a real life situation. A case-study approach can be used within units or subjects to help students analyse puzzling or unexpected events through subject reasoning. Therefore, this research examines the characteristics of the five elements of activity theory together with teaching methods. Researchers believe that the fit between teaching methods and the process of task or activities should enhance knowledge assimilation, which in turn leads to creative thinking.

\section{Research Methodology}

This research was conducted with graduate students studying business research methodology at a government-sponsored university in Thailand. The total participant count was 100 students in two semesters over one year. As research can be classified as quantitative or qualitative, this paper focuses on methods to teach quantitative research. Students in each semester were divided into groups to complete assigned research projects. Each group selected their own research topic. Each semester was divided into fifteen sessions of three hours in each session. Six sessions were used to teach research concepts and processes, emphasizing quantitative research. Two sessions were used to teach qualitative research, while five sessions focused on statistics. The last two sessions were used for research presentations by each group. These sessions allowed students in each group to present their conceptual models to the other groups in order to be evaluated for originality and uniqueness (Palaniappan, 2014). Figure 1 outlines the chronological sequence of this study. The process included two cycles: developing instructional methods to encourage creative thinking, and testing those instructional methods.

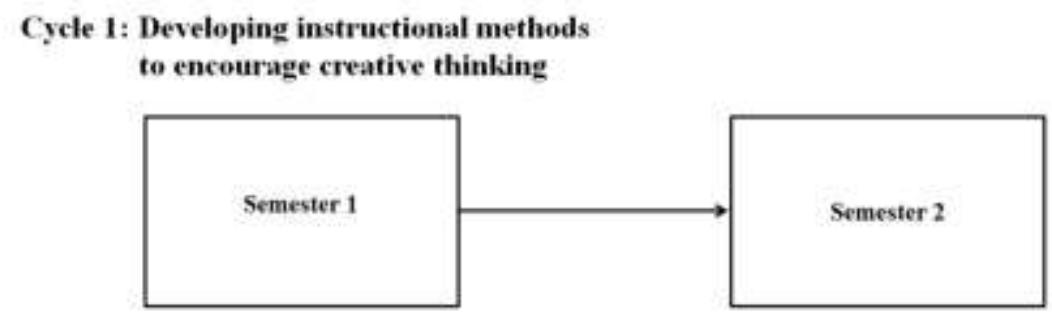

Cycle 2: Testing instructional methods developed in Cycle 1

Figure 1. Chronological Sequence of this Study

The explanation of each cycle is as follows:

Cycle 1 is developing instructional methods to encourage creative thinking. In this cycle, instructors adopt Plan (identifying the problems and planning the teaching), Act (delivering the teaching), Observe (collecting data), and Reflect (evaluating the results) are as follows:

- Before lecturing in each course session, instructors ask students in each group to finish a case study within 30 minutes. After this assignment is completed, the instructor provides a possible answer for the case study and explains research concepts supporting this answer. In addition, instructors encourage students to use their logical 
thinking to solve case-study questions. Examples of case-study questions are "is this case study topic relevant for business?" or "does the relationship among factors in the conceptual model make sense?" Instructors use three case studies to teach research concepts. One for defining research problems, another for building a conceptual model (or theory building), and the last for designing questionnaires. At the same time, other instructors teach statistical concepts and then ask students to finish three statistics case studies, including selecting appropriate statistical measures, analysing research results, and summarizing results.

- Apart from working on case studies, each group is required to complete and make two presentations on their own research project. The first presentation is the research proposal. After this first presentation, instructors ask a representative from each group to participate in a focus group. The objectives of the focus group are to extract (1) any significant information that may hinder students' creative thinking to develop a conceptual model and (2) any problems that have not been posted or discussed yet on the collaborative webboard. Each focus group takes three hours. The second presentation is the completed research report.

- Instructors answer questions asked by the students, while at the same time encouraging them to develop their research, especially the conceptual model, by using logical analysis. In addition, students in each group receive comments related to their research project. These comments come from an instructor who is an expert in the students' research topic, and two instructors of research methodology. Students from other groups may comment as well. The course instructors review the comments and make suggestions on how to improve the research, and then distribute to all students.

- Instructors assess students' creative thinking ability by analysing their research papers, together with reviewing discussions on the collaborative webboard. The primary focus is on the conceptual model because this part of the research project indicates whether or not students apply logical thinking, and in turn, creative thinking on their research projects.

- Lessons learned from this process are applied in future research methodology courses.

Cycle 2 is testing instructional methods developed in Cycle 1. This step is done in the same manner as in Cycle 1.

The materials and instruments used in this research consist of comprehensive notes for teaching research processes, six assignments (in the form of case studies) and collaborative technologies (e.g., webboard). Case studies are developed from students' research papers in previous semesters. Three case studies - for defining research problems, building a conceptual model (or theory building), and designing a questionnaire - are used to emphasize the use of logical thinking. The other three statistics case studies - for selecting statistical measures, analysing research results, and summarizing results - are used to help students understand the foundations of statistical knowledge. Apart from the free collaborative technologies (e.g., Facebook or Line), a proprietary webboard called ResYouAsk webboard (incorporating chats and discussion forums) are utilized. Students use these forums to post their problems when doing research projects and get feedback from instructors, normally within one day. For chats, students and instructors discuss students' research projects at an assigned specific time. Figure 2 shows two shot screens for Res YouAsk webboard. 


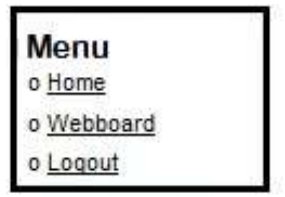

\begin{tabular}{|c|c|c|c|}
\hline & & & (6) ตั้งกระที้ใหน \\
\hline ล่าผับที & หั้ข้อ & โพสว่าสดโดอ & ตั้งกระทู้โดอ \\
\hline \multicolumn{4}{|c|}{ Student Community } \\
\hline 1 & G1Q1 (อ่าน 3/ตอบ 3) & $\begin{array}{l}\text { admin 2015-02-13 } \\
08: 19\end{array}$ & $\begin{array}{l}\text { admin } 2015-02-13 \\
06: 19\end{array}$ \\
\hline 2 & G1Q2 (อ่าน $2 /$ ตอบ 2) & $\begin{array}{l}\text { admin 2015-02-12 } \\
08: 30\end{array}$ & $\begin{array}{l}\text { G1N1 2015-02-12 } \\
07: 11\end{array}$ \\
\hline 3 & $\underline{\mathrm{G} 2 Q 1}$ (อ่าน 1/ตอบ 1) & $\begin{array}{l}\text { admin } 2015-02-20 \\
21: 00\end{array}$ & $\begin{array}{l}\text { admin } 2015-02-20 \\
18: 05\end{array}$ \\
\hline 4 & $\underline{\mathrm{G} 2 \mathrm{Q} 2}$ (อ่าน 1/ตอบ 1) & $\begin{array}{l}\text { admin 2015-02-11 } \\
08: 10\end{array}$ & $\begin{array}{l}\text { G2N3 2015-02-10 } \\
08: 15\end{array}$ \\
\hline 5 & G3Q1 (อ่าน 3/ตอบ 3) & $\begin{array}{l}\text { admin 2015-02-14 } \\
07: 30\end{array}$ & $\begin{array}{l}\text { G3N4 2015-02-11 } \\
17: 50\end{array}$ \\
\hline$\overline{6}$ & G3Q2 (อ่าน 4/ตอบ 2) & $\begin{array}{l}\text { G3N1 2015-02-28 } \\
08: 00\end{array}$ & $\begin{array}{l}\text { G3N1 2015-02-20 } \\
21: 00\end{array}$ \\
\hline
\end{tabular}

\begin{tabular}{|l|}
\hline Menu \\
$\circ \underline{\text { Home }}$ \\
$\circ$ Webboard \\
$\circ$ Logout \\
\hline
\end{tabular}

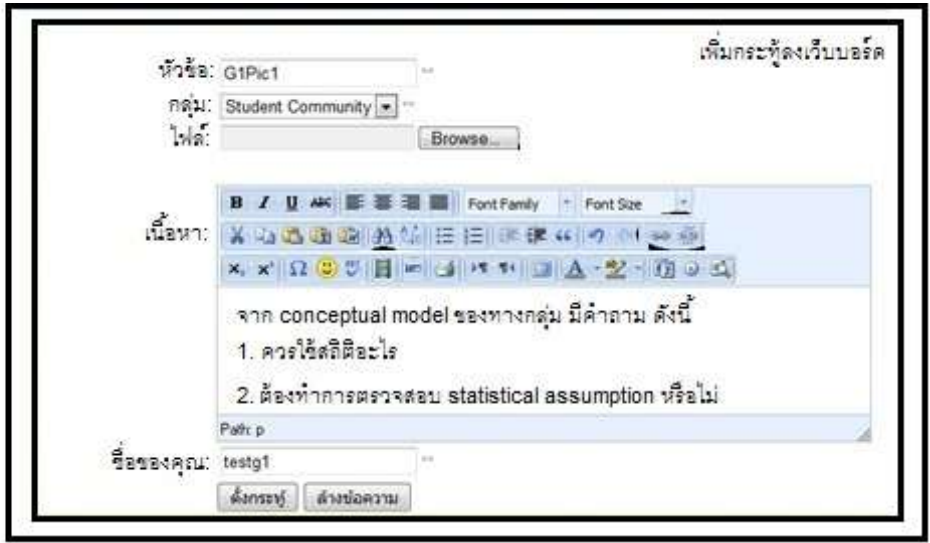

Figure 2. Two shot screens for Res YouAsk webboard

\section{Analysing the Results}

This research analyses students' creative thinking based on the attributes of their logical thinking, motivation to learn, response to collaborative learning, and compatibility with teaching methods.

\subsection{Cycle 1: Developing Instructional Methods to Encourage Creative Thinking}

\subsubsection{Identifying the Problem and Planning the Teaching}

The quality of students' literature reviews showed no improvement, with most citations not properly done. Each group of students usually cited previous research written in Thai language only. Some previous research cite dis not good quality. The main reasons for these problems are as follows: First, students cannot efficiently read through the prior research to gain an understanding of the main concepts. This is due to the fact that the students apparently lack sufficient ability in reading English. Second, students did not effectively learn research processes from the case studies developed in the previous semester, which consist of the major problems that the previous students encountered while studying research. Third, students commented that there is a lack of privacy when using Facebook for communication, especially when describing problems. In addition, instant communication (chat) via Facebook is not appropriate because students normally use nicknames for their Face book accounts. Instructors had difficulty in following the group progress because of the nicknames. Facebook also does not have $\log$ files to collect questions and ans wers which can be used as guidelines to analyse students' intellectual ability. Instructors can analyse a $\log$ file with text analysis statistical software for further data analysis. Fourth, collaboration among members in a group still was not appropriate. Each group normally divided research into separate tasks and then assigns these tasks to group members. Students then tend to work indi vidually instead of as a group. Fifth, regarding statistical analysis, students did not complain as much about the teaching process, except for the three statistics case studies. The students want case studies that better relate to their research project. The following information from focus group participants supports the above analysis. 
"It is difficult to read research papers and understand the main concepts, especially those written in English."

"Case studies at the beginning of each period consume too much time. In addition, the case studies are not relevant to my research topic."

"Sometimes I want to chat with instructors to get an instant answer, but the Facebook chat function does not work properly."

"Instructors should create Frequently Asked Questions (FAQs) so that students can use them as guidelines for their research papers."

"For my group, we created and assigned roles to each member. We divided the research paper into tasks which were assigned to each member. We also appointed one person to collect the completed tasks, and then consolidate them into one paper, while also correcting all errors."

From the problems noted above, the teaching plans were revised as follows. First, instructors still must continually encourage students to apply their logical thinking when de veloping their conceptual models. Second, to solve the problem of students' unsatisfactory citations of previous research papers, new criteria for students' literature review was established. Two-thirds of previous research cited should be in English, and should come from online databases provided by university libraries. Third, to promote ability to read research papers from journals, instructors prepared notes on how to read them to gain a proper understanding of the contents.

\subsubsection{Delivering the Teaching}

Teaching methods in this cycle are as follows: First, instructors continued to encourage students to use their logical thinking while de veloping conceptual models. For literature review, instructors explained and handed out notes on how to read research articles from journals. Second, case studies were revised to be less complex, take less time to finish, and better relate to students' research topics. Students still continued to work in groups to finish six case studies in a set schedule. Third, at the beginning of the semester, instructors asked students to form into groups. Roles were created for each member, and a group leader was selected. Each role has responsibility for a specific research task, while the group leader coordinated and consolidated the parts together. Fourth, the communication technology was changed from Facebook to Line. Line has chat and free-calling functionality, allowing instant response to questions posed by students. Fifth, three research presentations still are required because they help students to learn not only about the strengths and weaknesses of their research, but also about other research as well. Sixth, for statistical analysis, instructors taught statistical concepts and then had workshops with three adjusted (for complexity and time to complete) case studies. Instructors gave feedback to students during the workshops.

\subsubsection{Collecting Data}

To analyse whether the teaching process in this semester enhanced creative thinking in students, the following three methods were used to collect data for this research: (1) focus group, (2) research report at the end of the course, together with information posted by students on Line, the technology used for collaboration and (3) instructors' observations of students' learning.

\subsubsection{Evaluating the Results}

This research measured five components of creative thinking: innovation, feasibility, logic, flexibility, and clarity (Phillips, 2010). Innovation is the ability to generate new ideas for given problems. Feasibility is the ability to accomplish or bring about possible solutions to problems. Logic is the ability to think, especially in a reasonable manner while using good judgment. Flexibility is the ability to mix various theories in order to form new ideas. Clarity is the ability to elaborate or express an illustration of the argument. Because previous research indicated no weighting of these five components, it was decided to weight the five components equally. Each component is worth five points. Therefore, the total possible score for creative thinking is 25 points. The grading used for creative thinking ranges from 23-25 points for 'very, very good', 20-22 points for 'very good', 17-19 points for 'much better than average', 15-16 points for 'better than average but enough room for improvement', 13-14 points for 'better than average but just barely', and less than 12 points for 'needs lot of work to do'.

Two instructors evaluated the research reports from each group for creative thinking. The overall score for students this semester was 16 points. The score indicates that this semester's students are still better than average. But, in other words, the students still do not possess much creative thinking. In addition, Cohen's Kappa coefficient was used to calculate the consistency evaluation by the two instructors. Cohen's Kappa is 0.74 , which is higher than 0.65 (Cohen, 1960). This result indicates the same direction of assessments by the instructors. The 
complaints from students regarding case studies and ability to use statistics still need to be resolved. The reasons for unsatisfactory research papers are explained in more detail in Cycle 2.

\subsection{Cycle 2: Testing Instructional Methods Developed in Cycle 1}

\subsubsection{Identifying the Problem and Planning the Teaching}

The major problems encountered during cycle 1 is as follows: First, using case studies developed from the previous semester to teach students proved that these teaching methods are not appropriate. The way to teach research processes to students needed to be adjusted. The reasons are: (1) Time for students to complete case studies is limited. (2) Students lack motivation to do the case studies because they think they are difficult and time consuming. In addition, the case studies do not relate to their research projects and do not help students to make progress on them. Second, students complain about the comprehensive handouts. The handouts contain too much information regarding research processes which overloaded students' ability to learn. Third, group members have various interests and experiences that caused problems in working together and decision making. Fourth, technology communication still needed to be adjusted. Using Line to communicate still had problems. Line is not suitable if the network is not stable. In addition, Line does not have log files. The following information from focus group participants supports the above analysis:

"The case studies used in the workshops are not relevant to our research topics."

"Though the workshops help us to understand experiences with research from the previous semester, they consume too much time without any benefits for our research topics."

"The comprehensive handouts have too much information on research processes which confuse me."

"When we consult with instructors regarding our research using Line, the network always disconnects, and we are frustrated by this. Meeting instructors face to face may be more appropriate."

From the problems identified above, the teaching plans were revised as follows: First, instructors decided not to keep but to discard case studies from the previous semester. However, instructors retained the objectives of the case studies; i.e., encouraging students to successfully prepare problem statements, research objectives, research questions, conceptual models, and statistical analysis. Instructors designed case studies based on students' research projects assigned to be completed for this course. Students in each group worked on the ir research topics during classes. This allowed prompt responses from instructors when issues arose. Second, at the beginning of the semester, instructors asked students to form groups and establish roles for each member of the group, especially for the group leader. Third, a new technology communication was established. A proprietary collaborative webboard called ResYouAsk has functionality that allows students to post questions via discussion forums or chatting. In addition, this technology has log files so all questions and answers can be stored for further analysis.

\subsubsection{Delivering the Teaching}

Teaching methods in this cycle are as follows: First, instructors encouraged students to use their logical thinking as noted in cycle 1 . Instructors decided to provide lecture notes, instead of providing comprehensive handouts. These notes will be distributed to students at the beginning of each class. The notes incorporate (1) research processes and their relationship to research problems, research objectives, research questions, and research hypotheses (2) how to properly do literature reviews together with how to read previous research articles (3) theory building (4) questionnaire development (5) sampling (6) statistics selection (7) statistical analysis and writing results (8) writing completed research report. Second, instructors continued to form students into groups, along with establishing roles for each member in the group. Third, apart from using the technology communication stated above, students are able to consult with instructors after class. Fourth, instructors summarized FAQs created from the collaborative webboard log files and distributed these to students. Fifth, the six case studies were changed to be based on the students' research projects required for this course.

\subsubsection{Collecting Data}

Three methodologies for data collection - focus groups with students, students' research reports at the end of research course, and information posted by students on the Res YouAsk collaborative webboard - were used to collect data for this research.

\subsubsection{Evaluating the Results}

Instructors concluded that instructional methods used in semester 2 are suitable for teaching a research 
methodology course. In addition, the assessment of students' creative thinking from the two instructors showed satisfactory results. The assessment indicates that students in this semester got 19 points - much better than average. The consistency of assessment results of the two instructors calculated using Cohen's Kappa coefficient equals 0.79 . In addition, students were motivated to attend class, especially workshops using students' research projects as case studies, because they could finish their research projects during classes. Problems of collaboration were reduced when the groups had group leaders who are responsible to review all work of group members.

\section{Conclusions}

This research was initiated because instructors in business research methodology determined that most students do not master the most important objective of learning how to do research - to develop new knowledge. From analysing conceptual models and statistical analyses in students' research reports, instructors observed that students do not apply logical thinking skills. The students do not analyse and synthesize previous research articles properly. Students do not analyse statistics with appropriate procedures. Therefore, this research tries to answer questions on how to create creative thinking in business research classes by encouraging students' logical thinking, motivation, and collaborative learning.

The research results indicate that best-in-practice teaching procedures for the research subject are as follows: First, instructors should encourage students to use logical reasoning during conceptual framework development and data collection. Instructors should exchange problem-solving experiences with students. Second, instructors should provide handouts for further reading, such as how to read prior research and utilize suitable statistics. Third, apart from lectures, workshops during classes should be conducted so students can practice doing research. This enables students to discuss issues with instructors face to face and immediately. Fourth, additional sessions after class should be set up to allow students to discuss problems that they encounter with their research projects. Fifth, students have to finish a research project by the end of the semester. Sixth, students should make oral presentations on their projects and experts invited to comment on them. Seventh, teaching tools, such as collaborative technologies (e.g., ResYouAsk webboard), need to be introduced so that instructors and students can communicate with each other while not in class. Furthermore, these tools should have functionalities which suit students' and instructors' requirements, such as being able to post illustrations in any form (e.g., flow charts, diagrams), create log files and incorporate both chat and discussion forums. The limitation on this study is that the participants may not be suitable representatives of the whole population. Other samples from other universities should be examined.

Both theoretical and practical contributions were developed from this research: (1) For theoretical contributions, the initial research results indicate that logical thinking affects the analytical skill. This skill, in turn, affects students' creative thinking. However, three additional factors (feedback, motivation, and collaboration) need to be considered in teaching research methodology. Based on these results, the authors propose model of creating creative thinking in students, as shown in Figure 3. (2) For practical contributions, instructors should conduct class lectures together with workshops, for discussing and exchanging thoughts regarding students' research. Collaborative tools between instructors and students should be utilized to conveniently provide feedback. In addition, these tools can be used to monitor the progress of students.

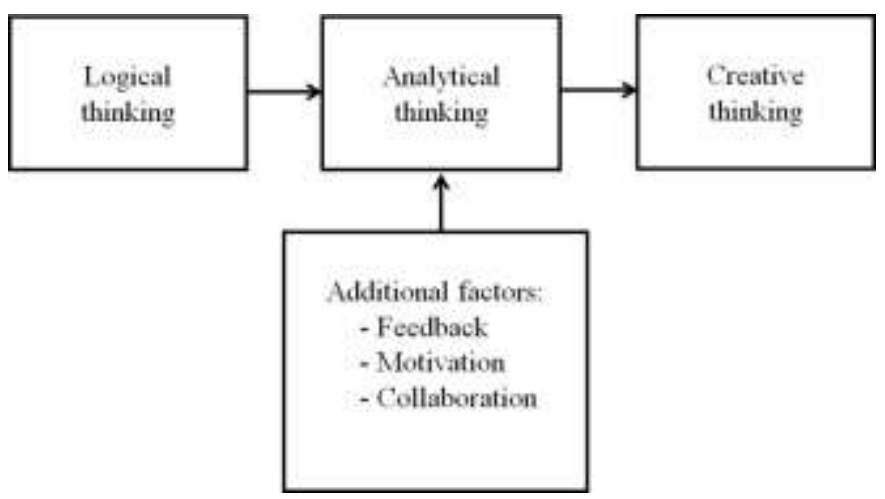

Figure 3. Model of Creating Creative Thinking

The research results indicate future research should be as follows: First, though this research incentivizes students by using scoring, this extrinsic motivation does not much impact the amount of effort students put into the research class. Students also have assignments from other classes that must be worked on, so workload 
balance is required. Therefore, this research results encourage further study to examine both intrinsic and extrinsic motivation, as suggested by Ryan and Deci (2000). Second, 45 hours per semester for a research class may not be enough for students to adequately understand the subject, especially for analysing and synthesizing prior literature. Therefore, future research should be designed to consider extending classroom time beyond 45 hours. This may lead students to commit more time to do learn research methods. Third, due to the limitation of time, instructors have to assign students to work on research assignments in groups. Some students within groups may not dedicate sufficient time to do their group assignments. Therefore, instructors should encourage collaboration among members within groups, which may affect knowledge building (Hong, 2011). Finally, as the third-cycle students' creative thinking scores indicate much better than average, the reason may be that this research emphasizes only the attributes of students. The attributes of instructors may affect methods to increase students' creative thinking (Palaniappan, 2014). Therefore, future research may need to investigate attributes of instructors in more detail.

\section{References}

Cavas, P. (2011). Factors affecting the motivation of Turkish primary students for science learning. Science Education International, 22(1), 31-42.

Cohen, J. (1960). A coefficient of agreement for nominal scales. Educational and Psychological Measurement, 20, 37-46. https://doi.org/10.1177/001316446002000104

Davis, D., Jindal-Snape, D., Digby, R., Howe, A., Collier, C., \& Hay, P. (2014). The roles and de velopment needs of teachers to promote creativity: Asystematic review of literature. Teaching and Teacher Education, 41, 34-41. https://doi.org/10.1016/j.tate.2014.03.003

Eining, M. M., \& Dorr, P. B. (1991). The Impact of Expert System Usage on Experiential Learning in an Auditing Setting. Journal of Information Systems, Spring, 1-16.

Engeström, Y., Miettinen, R., \& Punamäki, R. (1999). Perspectives on Activity Theory. UK: Cambridge University Press. https://doi.org/10.1017/CBO9780511812774

Gokhale, A. (1995). Collaborative learning enhances critical thinking. Journal of Technology Education, 7(1), 22-30. https://doi.org/10.21061/jte.v7i1.a.2

Gregor, S. (1996). Explanations from knowledge-based systems for human learning and problem solving. unpublished Ph.D. dissertation, University of Queensland, Australia.

Hong, H. (2011). Beyond Group Collaboration: Facilitating an Idea-centered View of Collaboration through Knowledge Building in a Science Class of Fifth-graders. The Asia-Pacific Education Researcher, 20(2), 246-260.

Horng, S., Hong, C., ChanLin, J., Chang, H., \& Chu, C. (2005). Creative teachers and creative teaching strategies. International Journal of Consumer Studies, 29(4), 352-358. https://doi.org/10.1111/j.1470-6431.2005.00445.x

Kyndt, E., Raes, E., Lismont, B., Timmers, F., Cascallar, E., \& Dochy, F. (2013). A meta-analysis of the effects of face-to-face cooperative learning. Do recent studies falsify or verify earlier findings? Educational Research Review, 10, 133-149. https://doi.org/10.1016/j.edurev.2013.02.002

Laney, D. (2001). Enhancing Economic Education through Improved Teaching Methods: Common Sense Made Easy. Subject-Specific Instructional Methods and Activities, 8, 411-435. https://doi.org/10.1016/S1479-3687(01)80035-3

Lau, J., \& Chan, J. (2004). What is critical thinking? Retrieved May 25, 2016, from http://philosophy.hku.hk/think/citical/ct.php

Mitnik, R, Recabarren, M., Nussbaum, M., \& Soto, A. (2009). Collaborative Robotic Instruction: A Graph Teaching Experience. Computers \& Education, 53(2), 330-342. https://doi.org/10.1016/j.compedu.2009.02.010

Morgan, C. R., \& Thiagarajan, P. (2009). The relationship between ethics, common sense, and rationality. Management Decision, 47(3), 481-490. https://doi.org/10.1108/00251740910946732

Murphy, D. (1990). Expert System Use and the Development of Expertise in Auditing: A Preliminary Investigation. Journal of Information Systems, fall, 18-35. 
Nimalathasan, B., \& Valeriu, B. (2010). Association between critical, creative thinking and problem solving in accounting researches: an overview. Revista Tinerior Economisti (The Young Economists Journal), 1(14), $7-12$.

Office of the National Economic and Social Development Board. (2015). The national economic and social development plan, issue 10 (2007-2011). Retrieved July 3, 2005, from http://www.nesdb.go.th/Default.aspx?tabid=139

Palaniappan, K. (2014). Evaluating creative and innovative teaching. Journal of social science research, 25-35.

Paul, R., \& Elder, L. (2011). Critical Thinking: Competency Standards Essential for the Cultivation of Intellectual Skills, Part 3. Journal of Development Education, 35(2), 34-35.

Phillips, C. (2010). 50 Puzzles for Creative Thinking. United Kingdom: Eddison Books Ltd.

Rimanoczy, I, (2007). Action reflection learning: a learning methodology based on common sense. Industrial and Commercial Training, 39(1), 43-51. https://doi.org/10.1108/00197850710721390

Ryan, M., \& Deci, E. (2000). Intrinsic and Extrinsic Motivations: Classic Definitions and New Directions. Contemporary Educational Psychology, 25, 54-67. https://doi.org/10.1006/ceps.1999.1020

Taylor, M. (2013). Six types of training and development techniques. Retrieved February 28, 2013, from http://ezinearticles.com/?Six-Types-of-Training-and-Development-Techniques\&id=1944536

Zhao, S. (2009). The nature and value of common sense to decision making. Management Decision, 47(3), 441-453. https://doi.org/10.1108/00251740910946705

\section{Copyrights}

Copyright for this article is retained by the author(s), with first publication rights granted to the journal.

This is an open-access article distributed under the terms and conditions of the Creative Commons Attribution license (http://creativecommons.org/licenses/by/4.0/). 